\title{
Fistula tembolok pada kakatua putih (Cacatua alba)
}

\author{
Intan Maria Paramita ${ }^{1}$, Leoisna Nirbhita Fajrin ${ }^{2}$, Ranin Oktrianinta ${ }^{2}$, Haris Darmawan $^{2}$ \\ ${ }^{1}$ Program Pendidikan Profesi Dokter Hewan, Fakultas Kedokteran Hewan, Institut Pertanian Bogor \\ ${ }^{2}$ Klinik Hewan Kayu Manis Yogyakarta
}

ABSTRAK: Pemeliharaan burung kakatua di Indonesia secara individual menyebabkan burung mudah mengalami stress dan menimbulkan perilaku feather pecking atau mencabuti bulunya sendiri. Perilaku ini dapat menyebabkan luka pada area yang bulunya dicabuti dan jika hal tersebut terjadi di area tembolok akan menyebabkan fistula tembolok. Fistula juga dapat disebabkan oleh kesalahan manajemen pakan dengan memberikan pakan terlalu banyak atau terlalu panas. Tembolok yang sudah berlubang dapat diperbaiki dengan melakukan penjahitan dan pemberian enrofloxacin secara oral. Pencegahan yang dapat dilakukan adalah dengan memperbaiki edukasi klien terkait manajemen pemberian pakan agar tidak terlalu banyak atau terlalu panas, dan juga terkait enrichment pada kakatua yang dipelihara secara individual.

Kata kunci:

fistula tembolok, kakatua putih

\section{- PENDAHULUAN}

Burung kakatua putih merupakan hewan cerdas yang hidup secara sosial dan cenderung suka berinteraksi dengan kakatua lainnya. Kakatua memerlukan partner dalam mengekspresikan perilaku alami seperti grooming satu sama lain. Pemeliharaan kakaktua di Indonesia masih belum memerhatikan hal ini. Kakatua biasa dipelihara secara sendirian atau ditinggal oleh klien dalam jangka waktu lama. Kakatua yang tidak dapat melakukan hal tersebut akan merasakan tertekan dan melakukan tindakan seperti mencabuti bulunya sendiri yang menyebabkan luka. Jika hal tersebut terjadi di daerah tembolok, maka dapat menyebabkan fistula tembolok. Fistula pada tembolok dapat menyebabkan pakan tidak dapat masuk kedalam lambung karena keluar melalui lubang pada tembolok. Jika hal tersebut terjadi secara terus menerus dapat menyebabkan malnutrisi pada kakatua. Pengetahuan terkait tingkah laku alami kakatua menjadi penting untuk mencegah terjadinya penyakit yang tidak diinginkan.

\section{- KASUS}

Seekor burung kakatua putih betina berumur empat bulan bernama Monty datang ke Klinik Hewan Kayu Manis Yogyakarta dengan keluhan terdapat lubang di daerah leher. Lubang ini mengakibatkan tubuh burung selalu basah karena air yang dikonsumsi keluar kembali melalui lubang tersebut. Namun lubang ini tidak mengganggu proses makan karena pakan yang dikonsumsi dapat masuk ke saluran pencernaan. Burung tersebut sering mematuki daerah luka ter- sebut sehingga lubang tersebut menjadi semakin besar. Hasil pemeriksaan menunjukkan bahwa burung kakatua putih mengalami fistula pada tembolok. Kejadian ini memiliki prognosa yang baik atau fausta.

\section{- HASIL DAN PEMBAHASAN}

Burung kakatua dalam kasus ini diberikan terapi berupa perbaikan fistula dengan melakukan penjahitan pada lubang tembolok serta diberikan antibiotik oral Enrofloxacin (․ Pemberian antibiotik dilakukan secara oral dengan bantuan syring yang dimodifikasi. Ujung syring dipasangkan plastic sheath dari IV catheter kucing atau anjing untuk memudahkan proses pemberian obat secara force feeding pada kakatua dan burung burung lainnya (Gambar 1).

Proses penjahitan dimulai dengan restraint pada burung. Burung di lakukan pengendalian mekanik tanpa pengendalian kimiawi. Burung dipegang di daerah tengkuk dan kedua kakinya. Daerah leher mengalami luka terbuka (Gambar 1A). Luka tersebut berbentuk lubang yang dilapisi kerak kering. Kerak kering tersebut dibersihkan dari kulit, kemudian kulit dan otot dilukai menggunakan blade untuk membuat perdarahan sehingga mempercepat persembuhan (Gambar 1B). Lubang kemudian dijahit menggunakan benang catgut 3/0 dengan pola simple interupted suture (Gambar 1C). Jahitan dilakukan hingga seluruh lubang tertutup (Gambar 1D).

\footnotetext{
Diterima : 21 Juli 2017

Direvisi : 8 Agustus 2017

Disetujui : 11 Agustus 2017
} 
Setelah penjahitan, burung Monty menunjukkan perbaikan, namun burung Monty masih cenderung menggigiti leher sehingga luka kembali terbuka seminggu kemudian dan dilakukan penjahitan lagi di daerah tembolok. Burung Monty kemudian datang lagi dua minggu kemudian dengan keadaan luka semakin mengecil. Burung Monty dinyatakan sembuh dua bulan setelahnya karena lukanya telah tertutup sempurna dan tidak ada kebocoran dari tembolok.

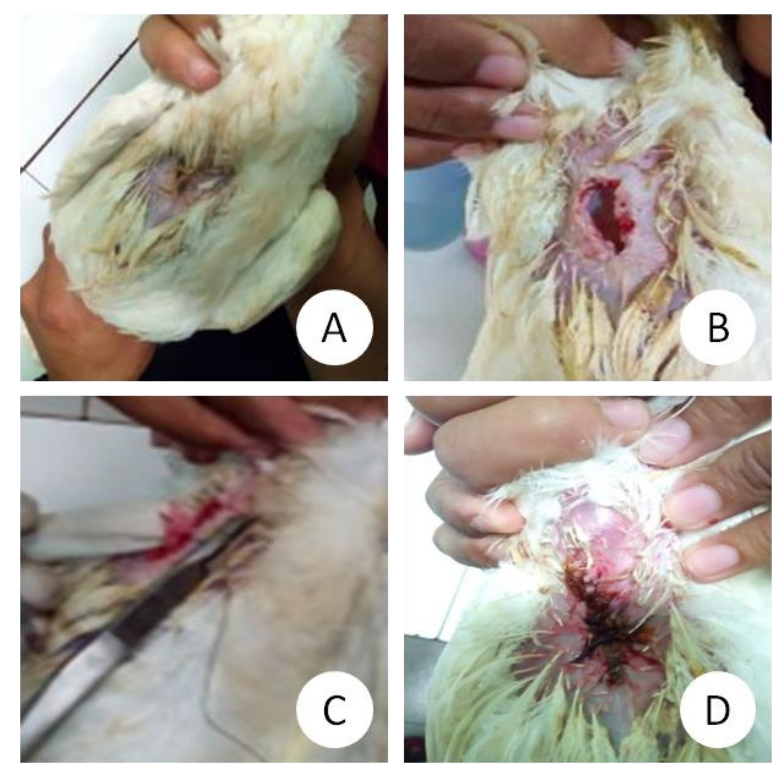

Gambar 1 Proses penjahitan tembolok.

Kejadian fistula pada tembolok dilaporkan pernah terjadi pada burung kakatua putih berumur 18 minggu. Gejala yang ditampilkan adalah vokalisasi yang terus menerus, serta regurgitasi. Burung kakatua tersebut diberi pakan komersial berupa pakan khusus bayi burung yang dipanaskan di microwave sebelum diberikan.Burung kakatua tersebut masih sangat aktif dan waspada. Temboloknya kosong, namun ketika dipalpasi teraba terdapat penebalan jaringan. Saat bulu disibakkan, ditemukan perlukaan pada kulit yang membentuk lubang. Burung tersebut kemudian diberikan antimikroba (nystatin dan trimetrophim sulfa) selama 10 hari, serta disarankan untuk memberikan pakan dalam jumlah lebih sedikit dengan proses pemanasan yang diperhatikan. Fistula tersebut kemudian ditutup dengan cara dilakukan penjahitan (Hoefer 2012).

Selain karena pakan, fistula tembolok juga dapat terjadi diawali dengan kejadian luka pada daerah leher. Luka tersebut dapat terjadi akibat kelainan perilaku (feather pecking) akibat burung tersebut mengalami stress. Burung kakatua di alam merupakan burung sosial yang hidup dengan partner. Burung tersebut biasanya akan saling melakukan grooming satu sama lain. Saat burung kakatua dipisahkan dan dipelihara sendiri burung tersebut akan mengalami rasa takut dan cenderung melalukan over grooming pada bulunya sendiri
(Van Zeeland et al. 2009). Hal ini yang menimbulkan terjadinya luka kecil dan bila dibiarkan akan terus menjadi luka besar dan mengakibatkan tembolok ikut berlubang dan membentuk fistula. Tindakan pada burung yang mengalami kejadian ini selain perbaikan dan manajemen luka juga diperlukan pengayaan.Salah satunya adalah dengan memberikan teman, baik itu berupa burung kakatua, ataupun boneka. Klien juga diharapkan dapat menjadi teman yang baik bagi burung kakatua dan tidak meninggalkan kakatua sendirian dalam waktu yang lama.

\section{- SIMPULAN}

Terapi yang diberikan pada kakatua Monty sudah sesuai dengan prosedur yang disarankan oleh beberapa literatur. Hasil terapi sudah cukup baik dibuktikan dengan menutupnya luka yang terbentuk. Pencegahan yang dapat dilakukan adalah dengan memerhatikan pakan yang akan diberikan kepada burung. Selain itu hal yang paling penting adalah memberikan pengayaan terutama pada kakatua yang dipelihara sendirian untuk mengurangi kejadian stress.

\section{- INFORMASI PENULIS}

Penulis untuk Korespondensi

vetinmarparamita@gmail.com

\section{Persetujuan Penulis}

Seluruh kontributor telah menyetujui publikasi paper ini.

\section{n UCAPAN TERIMA KASIH}

Terima kasih penulis ucapkan kepada tim dokter hewan Klinik Hewan Kayu Manis Yogyakarta atas arahan dan bimbinganya kepada penulis.

\section{aCUAN PUSTAKA}

Hoefer HL. 2012. Crop Burn in an Umbrella Cockatoo. Compendium: Continuing Education for Veterinarians. 34(4):1.

Van Zeeland YRA, Spruit BM, Rodenburg B, Riedstra B, Van Hierden YM, Buitenhuis B, Korte M, Lumeij JT. 2009. Feather damaging behavior in parrots: A review with consideration of comparative aspects. Applied Animal Behaviour Science. 121: 75-95. 